\title{
A decline in inflammation is associated with less depressive symptoms after a dietary intervention in metabolic syndrome patients: a longitudinal study
}

Aurora Perez-Cornago ${ }^{1}$, Rocio de la Iglesia', Patricia Lopez-Legarrea ${ }^{1,2}$, Itziar Abete ${ }^{3}$, Santiago Navas-Carretero 1,4, Clara I Lacunza ${ }^{5}$, Francisca Lahortiga ${ }^{5}$, Miguel A Martinez-Gonzalez ${ }^{6}$, J Alfredo Martinez ${ }^{1,4^{*}}$ and $M$ Angeles Zulet ${ }^{1,4}$

\begin{abstract}
Background: Metabolic syndrome (MetS) and depression have become two prevalent diseases worldwide, whose interaction needs further investigation. Dietary treatment for weight loss in patients with MetS may improve depressive manifestations, however, the precise interactive pathways remain uncertain. Therefore, the aim of this study was to examine the effects of a hypocaloric diet designed to reduce MetS features on self-perceived depression and the possible underlying factors.

Methods: Sixty subjects (Age: $50 \pm 1$ y; BMl: $36.1 \pm 0.6 \mathrm{~kg} / \mathrm{m}^{2}$ ) with MetS were selected from the RESMENA study (control and intervention) after they completed the 6-months hypocaloric treatment and rated for depressive symptoms using the Beck Depression Inventory (BDI). Anthropometric and biochemical measurements including leptin, C-reactive protein (CRP) and insulin levels were evaluated.
\end{abstract}

Results: Depressive symptoms decreased during the weight loss intervention, with no differences between both dietary groups (control group $-4.2 \pm 0.8$ vs RESMENA group $-3.2 \pm 0.6, P=0.490$ ). The number of criteria of the MetS was higher among subjects with more somatic-related depressive symptoms at baseline $(B=1.032, P$-trend $=$ 0.017). After six months of dietary treatment, body weight decreased in all subjects ( $-8.7 \%$; confidence interval $(95 \% \mathrm{Cl})=7.0-9.7)$ and also self-perceived depression $(-37.9 \% ; 95 \% \mathrm{Cl}=2.7-4.9)$, as well as circulating leptin $(-20.1 \%$; $95 \% \mathrm{Cl}=1.8-6.8), \mathrm{CRP}(-42.8 \% ; 95 \% \mathrm{Cl}=0.6-3.0)$ and insulin $(-37.7 \% ; 95 \% \mathrm{Cl}=4.1-7.2)$ concentrations. The decrease in $\mathrm{BDI}$ was significantly associated with declines in body fat mass $(\mathrm{B}=0.34,95 \% \mathrm{Cl}=0.11-0.56)$ and also with the decrease in leptin ( $B=0.16,95 \% \mathrm{Cl}=0.04-0.28)$ and $C R P(B=0.24,95 \% \mathrm{Cl}=0.01-0.46)$ concentrations.

Conclusions: The decrease in depressive manifestations after a weight loss intervention was related with adiposity, CRP and leptin in subjects with MetS.

Trial registration: ClinicalTrials.gov: NCT01087086.

Keywords: Metabolic syndrome, Depression, Inflammation, Leptin, Hypocaloric diet, Adiposity

\footnotetext{
*Correspondence: jalfmtz@unav.es

'Department of Nutrition, Food Science and Physiology, University of

Navarra, Irunlarrea 1, Pamplona 31008, Spain

${ }^{4}$ Carlos III Health Research Institute, CIBERobn, Physiopathology of Obesity

and Nutrition, Madrid, Spain

Full list of author information is available at the end of the article
}

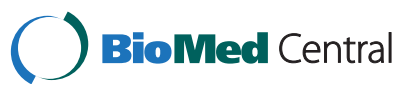

(c) 2014 Perez-Cornago et al.; licensee BioMed Central Ltd. This is an Open Access article distributed under the terms of the Creative Commons Attribution License (http://creativecommons.org/licenses/by/4.0), which permits unrestricted use, distribution, and reproduction in any medium, provided the original work is properly credited. The Creative Commons Public Domain Dedication waiver (http://creativecommons.org/publicdomain/zero/1.0/) applies to the data made available in this article, unless otherwise stated. 


\section{Background}

The metabolic Syndrome (MetS) is defined as a cluster of major cardiovascular risk factors including central obesity, glucose intolerance, hypertension and serum lipid disorders, whose prevalence is rapidly increasing worldwide [1,2]. Similarly, certain MetS features such as excessive adiposity, glucose intolerance and dyslipidemia, have been associated with depression [3], which is considered the fourth leading cause of disease burden in the world [4].

Because of the high prevalence and public health implications of both depression and MetS, the potential association between them has recently received much attention $[5,6]$. However, the exact interactive pathways between these diseases still remain uncertain, although they seem to be bidirectional and predisposed by both biochemical and behavioral mediators [6]. Depression involves dysregulation of the adrenocortical and autonomic nervous systems, which could increase MetS risk by favoring abdominal fat accumulation and insulin resistance [6]. Furthermore, subjects with MetS present increased levels of inflammatory cytokines and leptin resistance. Thus, C-reactive protein (CRP), a serum marker of systemic inflammation, has been a frequently investigated inflammatory marker in subjects with MetS [7]. Also, chronic inflammation could be involved in mood disorders, as a positive relationship between depression and CRP has been reported [8]. Regarding the association between depression and leptin, an adipokine mainly secreted by adipocytes with a key role in energy regulation, it seems that resistance to this hormone may contribute to higher depression rates in obese subjects [9].

Various strategies have been proposed to counteract MetS manifestations, including lifestyle (diet and exercise) modification and drug therapy based on antihypertensives, insulin sensitizers or therapies for dyslipidemia [10]. One of the most prescribed lifestyle changes is dietary treatment for weight loss, where the Mediterranean diet has been proven to be a useful tool to improve both MetS and depression symptoms [11,12]. Also, the psychological effects of weight loss approaches have been a matter of controversy, mainly regarding how changes in body weight correlate with depressive symptoms [13].

This research is based on a subsample of the RESMENA-S study [14-17], a randomized, controlled intervention study that aims to reduce MetS features using a hypocaloric diet during six months. In this article, we hypothesized that a hypocaloric treatment designed to reduce MetS features produces a positive effect on depressive symptoms, and we sought to explore the possible underlying mechanisms and interactions of this effect.

\section{Subjects and methods Subjects}

A total of ninety-three subjects $(52 \mathrm{M} / 41 \mathrm{~F})$ with a body mass index (BMI) of $36.1 \pm 0.6 \mathrm{~kg} / \mathrm{m}^{2}$ aged $50 \pm 1$ years diagnosed with MetS according to the IDF cut-offs [18] started the weight loss treatment. The inclusion and exclusion criteria have been previously reported [14-17], but it should be pointed out that subjects following antidepressant treatment were excluded as well as those with past mood disorders, including eating disorders. Also, vitamin or mineral supplements were not allowed.

After six months of weight loss intervention there were twenty-six dropouts due to loss to follow-up or consent withdrawal. Seven of the sixty-seven participants that finished the study did not complete all the Beck Depression Inventories (BDI). Therefore the present longitudinal study assessed the data from those 60 subjects (age: $50 \pm 1$ y.; $38 \mathrm{M} / 22 \mathrm{~F}$ ), who completed the BDI in the three main visits (baseline, after two months and at the end of the study), as described in the study flowchart (Figure 1).

In the RESMENA study, the CONSORT 2010 guidelines [19] were followed, and all the volunteers signed written informed consent before participating in the intervention study. The study protocol was performed in accordance with the ethical guidelines of the Declaration of Helsinki, and was approved by the Research Ethics Committee of the University of Navarra (ref. 065/2009).

\section{Study protocol}

The current study is based on a subsample of the RESMENA-S study, a randomized controlled intervention study aiming to improve clinical criteria and biomarkers associated with MetS through a dietary strategy for weight loss during six months. Briefly, participants were randomly assigned to follow one of the two energy-restricted diets, the control diet [20] or the RESMENA diet [14-17], both with the same energy restriction ( $-30 \%$ energy of the calculated requirements) by using the "random between 1 and 2" function in the Microsoft Office Excel 2003 software (Microsoft Iberica, Spain). The diets composition, as well as the different 48 - $\mathrm{h}$ dietary records, were analyzed by the DIAL (Alce Ingenieria, Madrid, Spain) software and described elsewhere [16,17].

The volunteers were asked to maintain their usual physical activity, which was controlled by a $24-\mathrm{h}$ physical activity questionnaire at the beginning and at the end of the study [21]. A psychological control using the BDI questionnaire was carried out at the main time points previously mentioned. More aspects of this intervention study have been previously detailed [14-17]. 


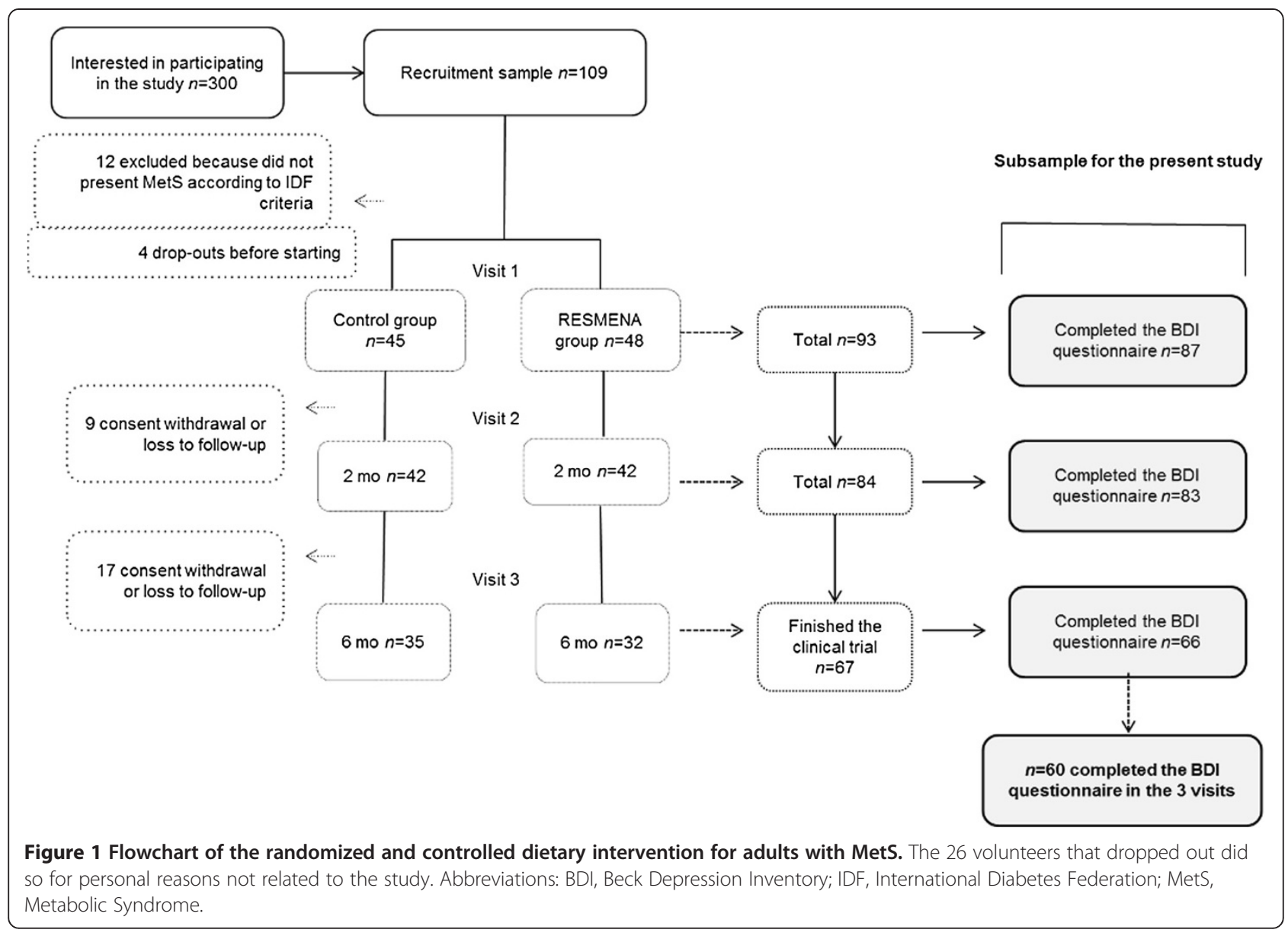

\section{Anthropometric and biochemical measurements}

Anthropometric and body composition measurements were taken following standardized procedures previously described [15-17].

Serum glucose, total cholesterol, HDL-cholesterol, triglycerides and free fatty acids serum concentrations were measured in an autoanalyser Pentra C-200 (HORIBA ABX, Madrid, Spain) with specific kits. Insulin concentrations were determined by an enzyme-linked immunosorbent assay (ELISA) kit (Mercodia, Uppsala, Sweden) using an automated analyser system (Triturus, Grifols, Barcelona). Serum insulin resistance was estimated by the Homeostasis Model Assessment Index (HOMA-IR) calculated with the following formula: HOMA-IR = fasting glucose $(\mathrm{mmol} / \mathrm{L}) x$ fasting insulin $(\mathrm{mU} / \mathrm{L})] / 22.5$ [22].

Plasma concentrations of CRP was assessed by an Immunodiagnostic AG kit (Bensheim, Germany) using an automated analyser system (Triturus, Grifols, Barcelona). Serum concentrations of leptin were measured using a RIA-based method (Diagnostic Products Corp., Los Angeles, CA).

\section{Assessment of depressive symptoms}

Symptoms of depression were assessed at the main three time points of the study (baseline, after two months and at the end of the study) using the Spanish version of the BDI [23], which is considered a validated and reliable measure of depressive symptoms $[24,25]$. A score $\geq 10$ reflects moderate depressive symptoms. The BDI questionnaire was divided into two subscales: the cognitive and the somatic symptom components. Question number 19 of the test, relating to weight loss, was discarded in some of the analyses given that losing weight is considered a depressive symptom, but our volunteers estimated it a positive aspect because they were enrolled in a weight loss treatment program [17].

\section{Statistical analyses}

The sample size for the main study (the RESMENA study) was calculated based on previous findings [26], where the mean difference in the waist circumference was $4.3 \mathrm{~cm}$ and the standard deviation (SD) was $6.8 \mathrm{~cm}$. To test the hypothesis of the present substudy and taking into account previous studies [27], a sample size of 
29 subjects would be enough to obtain a statistically significant difference in the reduction of BDI score $(2.2 \pm 2.5$ units), with an alpha error of $5 \%$ and a power of $90 \%$.

The main results were summarized as mean \pm SEM. Following published studies, the BDI score was analyzed as a continuous variable [9]. The Kolmogorow-Smirnov and the Shapiro Wilk test were used to analyze the normality of the measured variables. Analysis of covariance (ANCOVA) was used to assess changes between dietary treatments for the main dietary variables of the study, with sex and age as covariates. Changes in anthropometric and biochemical variables, as well as changes in the BDI questionnaire and physical activity level, were evaluated by repeated-measures ANOVA (three time points) or by using the nonparametric Friedman test when variables followed a non-normal distribution. Also, the effect of diet on these variables as well as the time-diet interaction was taken in consideration. A Bonferroni post hoc multiple comparison analysis was used when appropriate.

Tests of linear trend by increasing MetS criteria were conducted by assigning the mean value of BDI (somatic and cognitive questions separately) and modeling these values as a continuous variable. The changes in the cognitive and somatic questions (6 months - baseline) were assessed by ANCOVA with sex, age and dietary group as covariates. The association between changes (6 months baseline) in BDI questionnaire and changes (6 months baseline) total fat mass $(\mathrm{kg})$ was analyzed using multivariable linear regression analysis adjusted by sex, age and dietary group. For the association between changes in CRP, leptin and insulin with changes in BDI score three models were constructed: Model 1 included sex, age and dietary group variables. Model 2 included model 1 additionally adjusted for changes in activity level, and model 3 consisted of model 1 plus changes in total fat mass $(\mathrm{kg})$. All statistical analyses were carried out using SPSS 15.0 software for Windows (SPSS Ibérica, Madrid, Spain). Differences were considered statistically significant at $P<0.05$.

\section{Results}

The main dietary characteristics of the two prescribed diets were compared showing that, as expected, the RESMENA group consumed more protein than the Control group during the dietary treatment. Moreover, the RESMENA group showed a greater decrease in lipid intake, but lower intake of $\omega 3$ PUFA (Table 1). After six months of dietary treatment, subjects' anthropometric and biochemical variables improved significantly, observing a mean weight loss of $8.4 \pm 1.2 \mathrm{~kg}(P<0.001)$. However, there were no differences $(P \geq 0.10)$ between both dietary intervention groups in neither anthropometric nor biochemical variables, as well as activity level of the volunteers. Also, both Control and RESMENA diets proved to be equally effective on improving the BDI score (Table 2). Therefore, as no significant differences between dietary groups were found in any of the variables analyzed in this study, henceforth the two groups were merged and analyzed together as a unique experimental group.

The comparative analysis between completers $(n=62)$ and dropouts $(\mathrm{n}=25)$ concerning BDI score available at baseline, showed no significant differences $(P=0.255)$. Nonetheless, completers evidenced a lower mean value of BDI score at baseline $(7.6 \pm 0.7)$ in relation to those who did not finish the dietary treatment $(9.3 \pm 1.0)$.

The total number of subjects presenting a BDI score $\geq 10$ units at baseline was 25\% (9 M/6 F). After two months of weight loss treatment, this number decreased to $8.3 \%$ of the volunteers $(3 \mathrm{M} / 2 \mathrm{~F})$. At the end of the study ( 6 months later), only $6.6 \%$ of the subjects reported a BDI score $\geq 10$ (2 M/2 F).

A test of linear trend revealed that the higher the number of components of MetS according to IDF criteria (3, 4 or 5 components), the higher somatic BDI score at baseline. Interestingly, this association was not observed in the cognitive questions of the questionnaire (Figure 2).

In turn, losing more weight led to greater reductions $(P<0.013)$ in depressive symptoms (more weight loss $\Delta \mathrm{BDI}=-5.2 \pm 0.9$; vs less weight loss $\Delta \mathrm{BDI}=-2.5 \pm 0.6$ ). As expected, when we compared all the somatic-related questions separately between both groups (more weight loss vs less weight loss), significant differences were observed in the weight loss question, but also in the fatigability and loss of libido questions. Subjects reported losing more weight at 6 months than at baseline in the BDI questionnaire, hence the score of this question was higher at the end of the study. However, subjects who lost more weight did not show a greater reduction in the cognitive-related questions compared to individuals with lower body weight change (Figure 3).

Additionally, a positive association between changes in depressive symptoms and changes in $\mathrm{kg}$ of total fat mass was observed (Figure 4). We also found an association between changes in BDI score during the intervention period and changes in CRP, leptin and insulin levels. Further adjustment for body fat change eliminated the relation between depressive symptoms and insulin levels, however, the association of BDI with CRP and leptin remained statistically significant (Table 3 ).

\section{Discussion}

The present study reports an association of the reduction in depressive manifestations with the decrease in CRP and leptin after a dietary treatment for weight loss in subjects with MetS. Moreover, the reduction in fat mass was also involved in the decrease of depressive symptoms, but it was not implicated in the association of this variable with CRP and leptin. Previous investigations have reported a 
Table 1 Comparison of the two dietary treatments, control diet and RESMENA diet

\begin{tabular}{|c|c|c|c|c|c|}
\hline \multirow[b]{2}{*}{ Dietary intake } & \multicolumn{2}{|c|}{ Control group $(n=32)$} & \multicolumn{2}{|c|}{ RESMENA group $(n=28)$} & \multirow[t]{2}{*}{$P$ value } \\
\hline & Baseline & 6 months & Baseline & 6 months & \\
\hline Total energy intake, Kcal/d & $2108 \pm 69$ & $1535 \pm 54^{*}$ & $2279 \pm 99$ & $1573 \pm 72^{*}$ & 0.105 \\
\hline Proteins, g/d & $95.9 \pm 3.5$ & $66.9 \pm 3.4^{*}$ & $95.6 \pm 3.4$ & $79.3 \pm 3.4^{*}$ & 0.012 \\
\hline Carbohydrates, $g / d$ & $187.3 \pm 9.8$ & $142.6 \pm 8.1^{*}$ & $196.4 \pm 11.5$ & $138.9 \pm 6.2^{*}$ & 0.579 \\
\hline Lipids, g/d & $94.7 \pm 4.3$ & $69.1 \pm 2.9^{*}$ & $108.7 \pm 5.9$ & $67.0 \pm 3.8^{*}$ & 0.026 \\
\hline Fiber, $g / d$ & $21.4 \pm 1.8$ & $17.8 \pm 1.7$ & $22.6 \pm 1.1$ & $19.4 \pm 1.2$ & 0.748 \\
\hline Glycemic load & $106.6 \pm 8.6$ & $72.8 \pm 5.8^{*}$ & $112.1 \pm 7.4$ & $69.7 \pm 5.1^{*}$ & 0.491 \\
\hline$\omega 3$ PUFAs, $g / d$ & $0.28 \pm 0.01$ & $0.28 \pm 0.02$ & $0.35 \pm 0.16$ & $0.08 \pm 0.02^{*}$ & 0.002 \\
\hline Meal frequency, meals/d & $4.6 \pm 0.1$ & $4.5 \pm 0.1$ & $5.5 \pm 0.2$ & $5.9 \pm 0.2$ & 0.100 \\
\hline
\end{tabular}

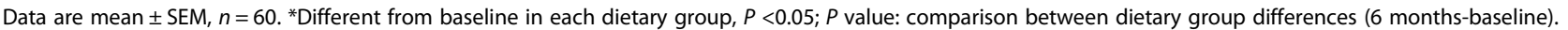
Abbreviations: $\omega 3$ PUFAs, omega-3 polyunsaturated fatty acids.

decrease in depressive manifestations after a weight loss treatment $[13,28]$, however, this study specifically demonstrates a relationship of the decrease in CRP and leptin with the reduction in self-perceived depression in subjects suffering MetS.

The domains of self-perceived depression were divided in cognitive and somatic questions in order to better interpret the primary cause of patient depression [29]. At baseline, there was a ranked relationship between increasing number of MetS components and a higher rate of somatic questions but not of cognitive components. These findings were similar to those observed in a previous study also based on self-reported BDI questionnaire [30].

Question number 19 of the BDI test, related to weight loss, was apparently distorting the total BDI score. This observation was confirmed because the weight loss was associated with the decrease in body weight at the end of the dietary treatment, showing that those subjects who lost most weight, had a higher score on the weight loss question of the test. Therefore, the weight loss question

Table 2 Anthropometric and biochemical variables in adults with MetS

\begin{tabular}{|c|c|c|c|c|c|c|}
\hline \multirow[b]{2}{*}{ Variables } & \multirow[b]{2}{*}{ Baseline } & \multirow[b]{2}{*}{2 months } & \multirow[b]{2}{*}{6 months } & \multicolumn{3}{|c|}{$P$ value } \\
\hline & & & & Time & Diet & TimexDiet \\
\hline Weight, $\mathrm{kg}$ & $102.8 \pm 2.2^{\mathrm{a}}$ & $95.4 \pm 2.1^{b}$ & $94.4 \pm 2.2^{b}$ & $<0.001$ & 0.834 & 0.666 \\
\hline $\mathrm{BMl}, \mathrm{kg} / \mathrm{m}^{2}$ & $36.1 \pm 0.6^{a}$ & $33.5 \pm 0.5^{b}$ & $33.2 \pm 0.6^{b}$ & $<0.001$ & 0.997 & 0.474 \\
\hline$W C, c m$ & $114.2 \pm 1.6^{\mathrm{a}}$ & $106.8 \pm 1.5^{\mathrm{b}}$ & $105.7 \pm 1.6^{\mathrm{b}}$ & $<0.001$ & 0.999 & 0.102 \\
\hline \multicolumn{7}{|l|}{ DXA measurements } \\
\hline Fat mass, $\mathrm{kg}$ & $42.9 \pm 1.2^{\mathrm{a}}$ & $37.5 \pm 1.2^{b}$ & $36.3 \pm 1.2^{c}$ & $<0.001^{1}$ & 0.469 & 0.432 \\
\hline Muscle mass, $\mathrm{kg}$ & $56.6 \pm 1.5^{\mathrm{a}}$ & $54.5 \pm 1.4^{b}$ & $54.8 \pm 1.5^{b}$ & $<0.001$ & 0.694 & 0.239 \\
\hline \multicolumn{7}{|l|}{ Biochemical variables } \\
\hline Cholesterol, mg/dL & $219 \pm 5^{a}$ & $197 \pm 5^{b}$ & $219 \pm 5^{a}$ & $<0.001$ & 0.568 & 0.751 \\
\hline Glucose, mg/dL & $128 \pm 5^{a}$ & $111 \pm 3^{b}$ & $116 \pm 4^{b}$ & $0.001^{1}$ & 0.786 & 0.377 \\
\hline $\mathrm{TG}, m g / d L$ & $195 \pm 13^{a}$ & $146 \pm 10^{b}$ & $154 \pm 12^{b}$ & $<0.001^{1}$ & 0.730 & 0.955 \\
\hline $\mathrm{FFA}, \mathrm{mmo} / \mathrm{L}$ & $0.56 \pm 0.21^{a}$ & $0.52 \pm 0.24^{\mathrm{a}, \mathrm{b}}$ & $0.47 \pm 0.20^{b}$ & 0.016 & 0.122 & 0.461 \\
\hline $\mathrm{CRP}, m g / L$ & $4.3 \pm 0.7^{\mathrm{a}}$ & $3.1 \pm 0.4^{\mathrm{a}, \mathrm{b}}$ & $2.5 \pm 0.4^{b}$ & $0.005^{1}$ & 0.597 & 0.183 \\
\hline HOMA index, $m M / L$ & $4.9 \pm 0.4^{a}$ & $2.8 \pm 0.3^{b}$ & $3.0 \pm 0.4^{b}$ & $<0.001$ & 0.956 & 0.288 \\
\hline Leptin, $n g / m L$ & $21.5 \pm 2.1^{a}$ & $14.5 \pm 1.5^{c}$ & $17.2 \pm 1.9^{\mathrm{b}}$ & $<0.001$ & 0.816 & 0.837 \\
\hline Insulin, $\mu U / m L$ & $15.4 \pm 1.1^{\mathrm{a}}$ & $9.7 \pm 0.9^{b}$ & $9.6 \pm 1.0^{b}$ & $<0.001^{1}$ & 0.964 & 0.634 \\
\hline $\mathrm{BDI}$ questionnaire & $7.6 \pm 0.8^{a}$ & $4.4 \pm 0.6^{b}$ & $3.8 \pm 0.7^{c}$ & $<0.001$ & 0.777 & 0.798 \\
\hline Activity level $^{2}$ & $1.6 \pm 0.1$ & $1.6 \pm 0.1$ & $1.6 \pm 0.1$ & 0.154 & 0.697 & 0.184 \\
\hline
\end{tabular}

Values are mean \pm SEM $n=57-60$. Effects of time, diet (control diet vs RESMENA diet) and time-diet interactions were analysed with repeated-measures ANOVA or Friedman test. Values in a row with different superscript letters $(\mathrm{a}, \mathrm{b}, \mathrm{c})$ are significantly different, $P<0.05$ by Bonferroni post hoc test, being a $>\mathrm{b}>\mathrm{c}$. Abbreviations: BDI, Beck Depression Inventory; BMl, body mass index; CRP, C-reactive protein; DXA, dual-energy X-ray absorptiometry; FFA, free fatty acids; MetS, Metabolic Syndrome; TG, triglycerides; WC, waist circumference.

${ }^{1} P$-value based on non-parametric Friedman test compared the three time points of the study.

${ }^{2}$ Average daily exercise calculated by twenty-four physical activity questionnaire. 


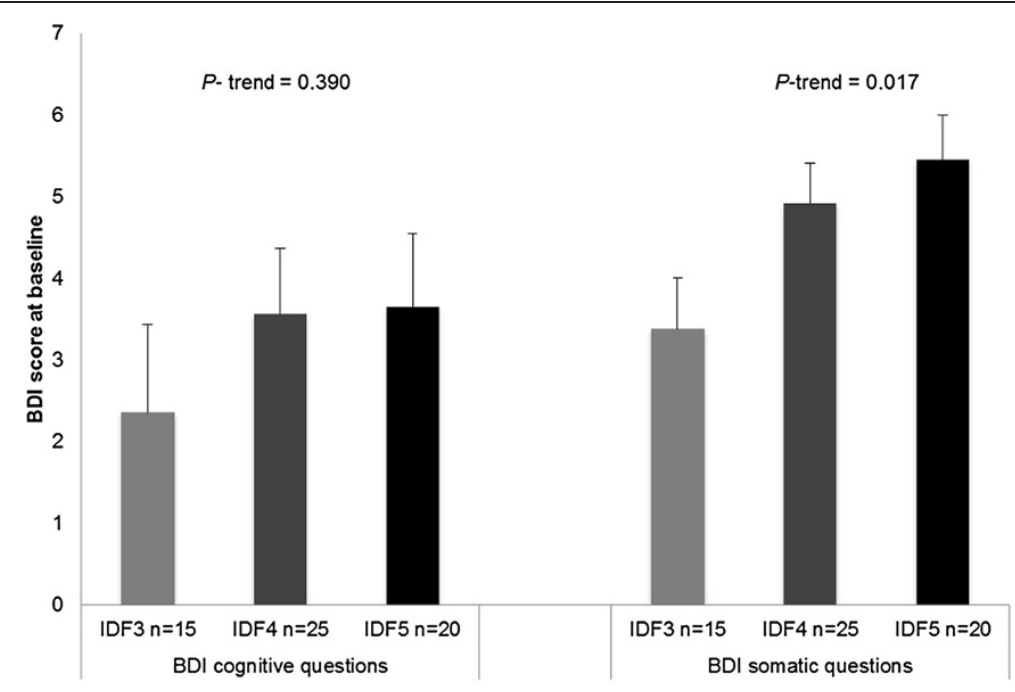

Figure 2 Association between the number of MetS components assessed by IDF criteria and the BDI score at baseline. Values are mean \pm SEM, $n=60$. BDI score divided by somatic and cognitive questions Abbreviations: BDI, Beck Depression Inventory; IDF, International Diabetes Federation.

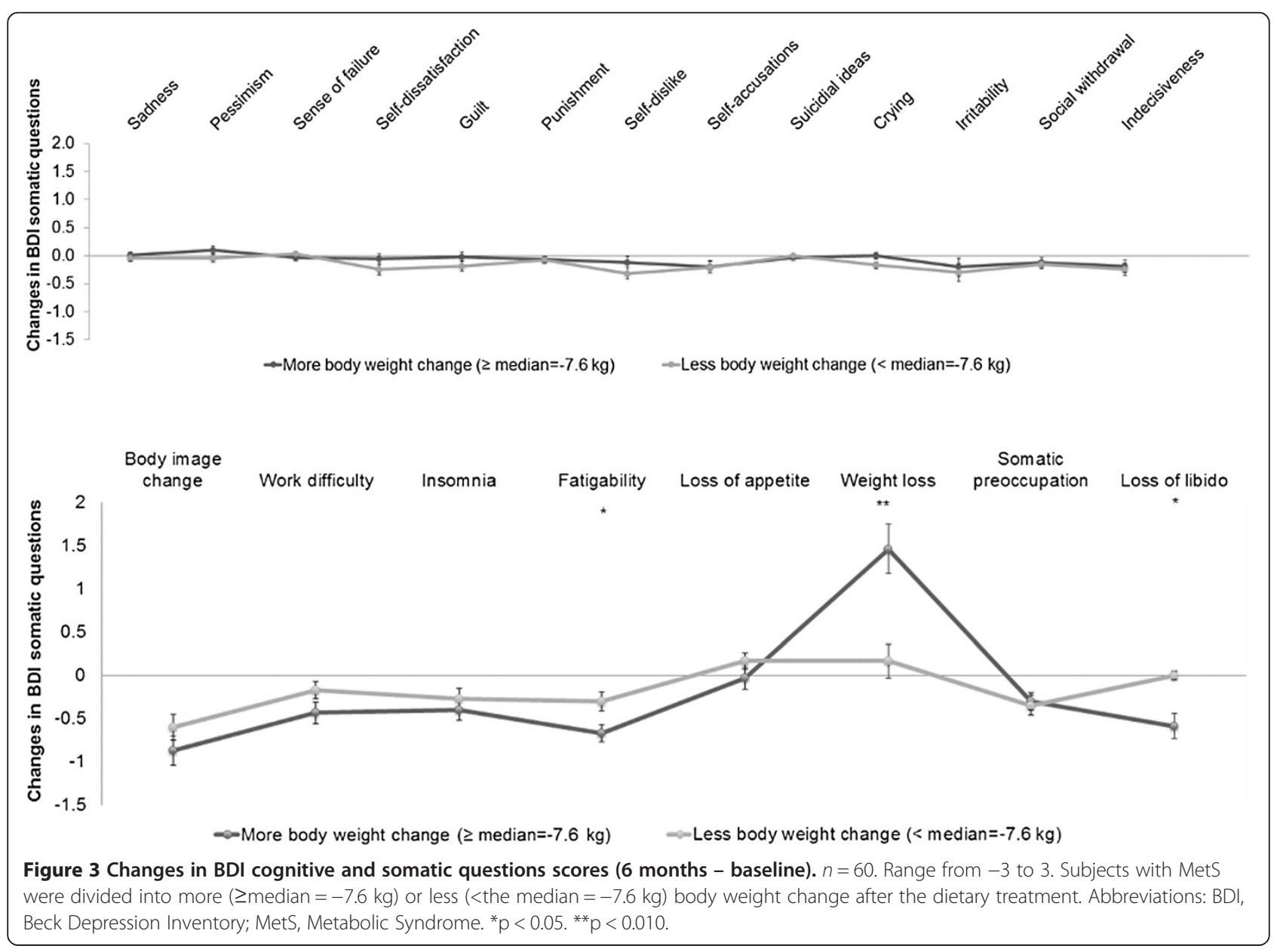




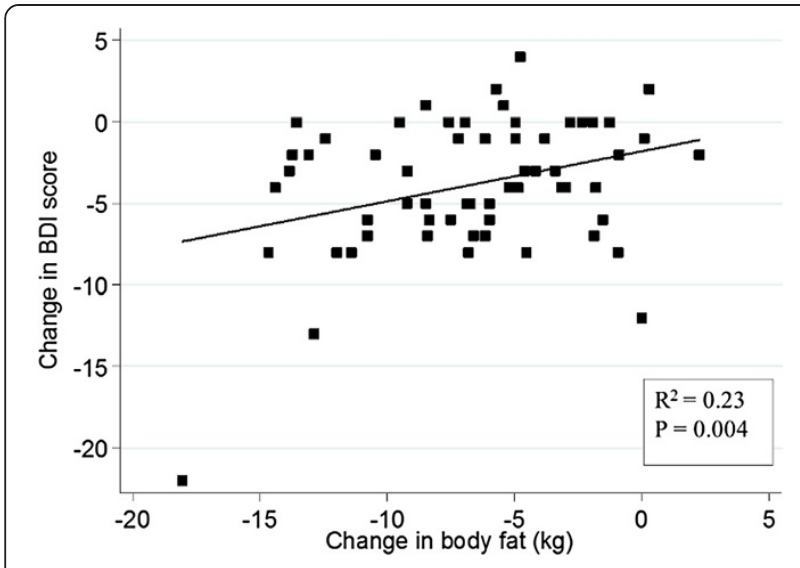

Figure 4 Association between changes in BDI score and changes in body fat (kg). Abbreviations: BDI, Beck Depression Inventory. Adjusted by sex, age and dietary group. Changes (6 months - baseline), $n=60$.

was removed from the total BDI score in some analyses. Moreover, the improvement in the fatigability and loss of libido questions (somatic-related questions) might be considered as benefits of the weight loss.

Noteworthy, a positive association between decreases in CRP values and reductions in depressive symptoms was observed as has been reported in previous studies [8]. Inflammation seems to be, in part, responsible for the link

Table 3 Association between changes in BDI score and changes in CRP, leptin and insulin

\begin{tabular}{llcc}
\hline & \multicolumn{3}{c}{ Change in BDI score } \\
\cline { 2 - 4 } Changes in: & B & 95\% Cl & p \\
\hline CRP mg/L & & & \\
Unadjusted model & 0.25 & 0.01 to 0.49 & 0.043 \\
Model 1 & 0.27 & 0.03 to 0.51 & 0.029 \\
Model 2 & 0.26 & 0.01 to 0.50 & 0.044 \\
Model 3 & 0.28 & 0.06 to 0.51 & 0.015 \\
Leptin ng/mL & & & \\
Unadjusted model & 0.18 & 0.07 to 0.29 & 0.002 \\
Model 1 & 0.21 & 0.10 to 0.32 & 0.001 \\
Model 2 & 0.22 & 0.08 to 0.36 & 0.012 \\
Model 3 & 0.17 & 0.04 to 0.30 & 0.013 \\
Insulin $\mu U / m L$ & & & \\
Unadjusted model & 0.21 & 0.02 to 0.40 & 0.026 \\
Model 1 & 0.25 & 0.07 to 0.42 & 0.006 \\
Model 2 & 0.33 & 0.15 to 0.52 & 0.001 \\
Model 3 & 0.18 & -0.01 to 0.36 & 0.059 \\
\hline
\end{tabular}

The table shows B coefficients ( $95 \% \mathrm{Cl}$ ) and p-value. Changes (6 months-baseline), $n=60$. Abbreviation: BDI, Beck Depression Inventory; CRP, C-reactive protein. Model 1: Adjusted by sex, age and dietary group. Model 2: Model 1 additionally adjusted for changes in activity level. Model 3: Model 1 additionally adjusted for changes in body fat $(\mathrm{kg})$. between depressive symptoms and MetS. However, the precise nature of this relationship is not clear [8]. Theoretically, the association of leptin with depression may be related both to its metabolic properties and neurobiological activities [9]. Leptin affects cognition and mood in the hippocampus, the cortex and other brain areas associated with cognition [9,31]. Obesity is related to higher levels of circulating leptin reflecting, in part, an increased formation of adipocytes, and causing leptin resistance in some obese subjects. A positive association between the decline in BDI score and the drop in leptin values was found, in line with results from previous studies [9,32]. Furthermore, in an unadjusted model, a positive association was noted between insulin and depressive symptoms, being this link well-established [33,34]. However, this association was no longer statistically significant when change in body fat was introduced in the model.

A previous weight loss intervention study showed that depression scores at baseline predicted adherence to a dietary treatment [28]. In accordance with this outcome, a higher BDI score in drop-outs at baseline was observed, although this value did not reach statistical significance. A positive association between lower BDI score and decreases in body weight was found, which is in agreement with previous studies [13]. In addition, there is some evidence suggesting that adiposity is directly related with depression [3]. In this study, the higher decrease in depressive symptoms was noticeable in those participants with a greater decline in total fat mass. Since adipose tissue is known to secrete inflammatory cytokines and leptin [35], it might be hypothesized that the decrease in body fat mass may have contributed to reduce CRP and leptin and subsequently decrease depressive symptoms.

Furthermore, the Mediterranean diet has been associated with reduced prevalence and incidence of MetS and depressive symptoms $[11,12]$. A healthy dietary pattern has been associated with better mood [36] and diets rich in $\omega 3$ PUFA may decrease serum cytokine production and depressive signs [37]. Also, an inverse association between both vitamin $\mathrm{D}$ and vitamin $\mathrm{C}$ levels with depressive symptoms has been observed [38,39]. In this context, we have previously shown that folate intake during this dietary intervention was well correlated with the decrease in depressive symptoms [17].

Because both MetS and depressive manifestations seem to share several common mechanisms, it has been suggested that the dietary recommendations for MetS might be helpful for depression treatment [5]. The present study strengthens this hypothesis, as the dietary treatment for MetS manifestations also reduced depressive symptoms. Moreover, several unhealthy lifestyle habits have been related with depressive symptoms, such as fast food consumption, high fat intake or low physical activity [5,40]. In this study, physical activity was not directly associated 
with depressive symptoms, being in agreement with previous investigations [41].

The control diet based on the AHA guidelines is a well-design strategy for weight loss [20], what may explain that no differences between dietary groups were observed in the variables analyzed in this study. As both dietary groups proved to be effective in reducing depressive symptoms and no differences between them were found, both groups were merged and analyzed together as a unique experimental group. A longitudinal observational analysis comparing the BDI scores before and after intervention was conducted, serving the volunteers as their own control. The clear differences between the beginning and the end of the study lend support to the soundness of the analysis. One of the strengths of withinsubjects (paired) analyses is the reduction in error variance associated with individual differences, which increases statistical power. Moreover, in order to control the possible confounding role of the intervention group, this variable was included in the multiple-adjusted models investigating the association of anthropometric and biochemical variables with depressive manifestations in the complete sample [17].

The study has some limitations. Firstly, depressive symptoms were evaluated using a self-report questionnaire, the Beck Depression Inventory, which is not designed as a diagnostic tool but as a screening method [24]. However, this test was chosen as it is widely recognized, it has been shown to be valid for clinical assessment [25] and it has previously been used to record depressive symptoms in weight loss studies $[13,28]$. Secondly, this study only aimed to evaluate the association between the variables included and it cannot be determined any conclusions on causality between changes in body weight, fat mass, leptin and CRP and changes in depressive symptoms. In addition, the prevalence of depressive symptoms in our sample was low, which can be explained with the fact that subjects presenting psychiatric disorders at enrollment were not allowed to participate in the study. Also, the number of participants in this study is not very high, but it may be proposed that type-II errors were overcome since important statistical differences were found.

\section{Conclusions}

In conclusion, this study shows an association of the reduction in depressive manifestations with CRP and leptin in subjects with MetS after following a weight loss treatment. Interestingly, the decrease in fat mass was also related with the reduction of depressive symptoms. More studies are needed to explore the mechanisms underlying the MetS-depression relationship, which may be decisive for the prevention and treatment of both conditions.

\section{Competing interests}

The authors declared that they have no competing interests.

\section{Authors' contributions}

The authors contributions were as follows: APC performed the research, analysed data and wrote the manuscript; RI, PLL, IA and SNC conducted research; FL and CIL selected and contributed to the interpretation of the psychological test; MAM contributed to the statistical analysis. JAM and MAZ designed and managed the research, and had primary responsibility for final content. All the authors read and approved the final version of the manuscript.

\section{Acknowledgements}

We wish to thank the volunteers of this study and Blanca E. Martínez de Morentín, Salomé Pérez, as well as Verónica Ciaurriz for excellent technical assistance in the University of Navarra. We would like to thank Dr Paul W. Miller from the Institute of Modern Languages of the University of Navarra for careful reading the manuscript.

\section{Author details}

${ }^{1}$ Department of Nutrition, Food Science and Physiology, University of Navarra, Irunlarrea 1, Pamplona 31008, Spain. ${ }^{2}$ Faculty of Health Science, Universidad Autonoma de Chile, Santiago, Chile. ${ }^{3}$ Biodonostia Health Research Institute, Doctor Begiristain (no number), 20014, San Sebastian, Spain. ${ }^{4}$ Carlos III Health Research Institute, CIBERobn, Physiopathology of Obesity and Nutrition, Madrid, Spain. ${ }^{5}$ Department of Psychiatry and Medical Psychology, University Clinic of Navarra, Pio XII 36, Pamplona 31008, Spain. ${ }^{6}$ Department of Preventive Medicine and Public Health, University of Navarra, Irunlarrea 1, Pamplona 31008, Spain.

Received: 2 March 2014 Accepted: 15 April 2014

Published: 24 April 2014

\section{References}

1. Yamaoka K, Tango T: Effects of lifestyle modification on metabolic syndrome: a systematic review and meta-analysis. BMC Med 2012, 10:138.

2. Yanai $H$, Tomono $Y$, Ito $K$, Furutani N, Yoshida H, Tada N: The underlying mechanisms for development of hypertension in the metabolic syndrome. Nutr J 2008, 7:10.

3. Murabito JM, Massaro JM, Clifford B, Hoffmann U, Fox CS: Depressive symptoms are associated with visceral adiposity in a community-based sample of middle-aged women and men. Obesity 2013, 21:1713-1719.

4. Ustun TB, Ayuso-Mateos JL, Chatterji S, Mathers C, Murray CJ: Global burden of depressive disorders in the year 2000. Br J Psychiatry 2004, 184:386-392.

5. Sanchez-Villegas A, Martinez-Gonzalez MA: Diet, a new target to prevent depression? BMC Med 2013, 11:3.

6. Pan A, Keum N, Okereke OI, Sun Q, Kivimaki M, Rubin RR, Hu FB. Bidirectional association between depression and metabolic syndrome: a systematic review and meta-analysis of epidemiological studies. Diabetes Care 2012, 35:1171-1180.

7. Kraja AT, Province MA, Arnett D, Wagenknecht L, Tang W, Hopkins PN, Djousse L, Borecki IB: Do inflammation and procoagulation biomarkers contribute to the metabolic syndrome cluster? Nut Metab 2007, 4:28.

8. Daly M: The relationship of C-reactive protein to obesity-related depressive symptoms: a longitudinal study. Obesity 2013, 21:248-250.

9. Morris AA, Ahmed Y, Stoyanova N, Hooper WC, De Staerke C, Gibbons G, Quyyumi A, Vaccarino V: The association between depression and leptin is mediated by adiposity. Psychosom Med 2012, 74:483-488.

10. Swislocki AL, Siegel D, Jialal I: Pharmacotherapy for the metabolic syndrome. Curr Vasc Pharmacol 2012, 10:187-205.

11. Salas-Salvado J, Bullo M, Babio N, Martinez-Gonzalez MA, Ibarrola-Jurado N, Basora J, Estruch R, Covas MI, Corella D, Aros F, Ruiz-Gutierrez V, Ros E: Reduction in the incidence of type 2 diabetes with the Mediterranean diet: results of the PREDIMED-Reus nutrition intervention randomized trial. Diabetes Care 2011, 34:14-19.

12. Sanchez-Villegas A, Delgado-Rodriguez M, Alonso A, Schlatter J, Lahortiga F, Serra Majem L, Martinez-Gonzalez MA: Association of the Mediterranean dietary pattern with the incidence of depression: the Seguimiento Universidad de Navarra/University of Navarra follow-up (SUN) cohort. Arch Gen Psychiatry 2009, 66:1090-1098.

13. Fabricatore AN, Wadden TA, Higginbotham AJ, Faulconbridge LF, Nguyen AM, Heymsfield SB, Faith MS: Intentional weight loss and changes in symptoms 
of depression: a systematic review and meta-analysis. Int J Obes 2011, 35:1363-1376

14. de la Iglesia R, Lopez-Legarrea P, Abete I, Bondia-Pons I, Navas-Carretero S, Forga $L$, Martinez JA, Zulet MA: A new dietary strategy for long-term treatment of the metabolic syndrome is compared with the American heart association (AHA) guidelines: the MEtabolic syndrome REduction in NAvarra (RESMENA) project. Bri J Nutr 2014, 111:643-652.

15. Lopez-Legarrea P, de la Iglesia R, Abete I, Bondia-Pons I, Navas-Carretero S, Forga $L$, Martinez JA, Zulet MA: Short-term role of the dietary total antioxidant capacity in two hypocaloric regimes on obese with metabolic syndrome symptoms: the RESMENA randomized controlled trial. Nutr Metab 2013, 10:22.

16. de la Iglesia R, Lopez-Legarrea P, Celada P, Sanchez-Muniz FJ, Martinez JA, Zulet MA: Beneficial effects of the RESMENA dietary pattern on oxidative stress in patients suffering from metabolic syndrome with hyperglycemia are associated to dietary TAC and fruit consumption. Int J Mol Sci 2013, 14:6903-6919.

17. Perez-Cornago A, Lopez-Legarrea P, de la Iglesia R, Lahortiga F, Martinez JA, Zulet MA: Longitudinal relationship of diet and oxidative stress with depressive symptoms in patients with metabolic syndrome after following a weight loss treatment: the RESMENA project. Clin Nutr 2013, http://dx.doi.org/10.1016/j.clnu.2013.11.011.

18. Alberti KG, Zimmet $P$, Shaw J: The metabolic syndrome-a new worldwide definition. Lancet 2005, 366:1059-1062.

19. Schulz KF, Altman DG, Moher D: CONSORT 2010 statement: updated guidelines for reporting parallel group randomised trials. BMJ 2010, 340:C332

20. Grundy SM, Cleeman JI, Daniels SR, Donato KA, Eckel RH, Franklin BA, Gordon DJ, Krauss RM, Savage PJ, Smith SC Jr, Spertus JA, Costa F: Diagnosis and management of the metabolic syndrome: an American heart association/national heart, lung, and blood institute scientific statement. Circulation 2005, 112:2735-2752.

21. Food and Nutrition Board NRC: Recommended dietary allowances. 10th edition. Washington, DC: The National Academy Press; 1989.

22. Matthews DR, Hosker JP, Rudenski AS, Naylor BA, Treacher DF, Turner RC Homeostasis model assessment: insulin resistance and beta-cell function from fasting plasma glucose and insulin concentrations in man. Diabetologia 1985, 28:412-419.

23. Conde C, Useros E: Adaptación castellana de la escala de evaluación conductual para la depresión de Beck. Rev Psiqiat Psicol Med 1975, 12:217-236.

24. Beck AT, Ward CH, Mendelson M, Mock J, Erbaugh J: An inventory for measuring depression. Arch Gen Psychiatry 1961, 4:561-571.

25. Davidson KW, Kupfer DJ, Bigger JT, Califf RM, Carney RM, Coyne JC, Czajkowsk SM, Frank E, Frasure-Smith N, Freedland KE, Froelicher ES, Glassman AH, Katon WJ, Kaufmann PG, Kessler RC, Kraemer HC, Krishnan KR, Lesperance F, Rieckmann N, Sheps DS, Suls JM: Assessment and treatment of depression in patients with cardiovascular disease: national heart, lung, and blood institute working group report. Ann Behav Med 2006, 32:121-126.

26. Katcher HI, Legro RS, Kunselman AR, Gillies PJ, Demers LM, Bagshaw DM, Kris-Etherton PM: The effects of a whole grain-enriched hypocaloric diet on cardiovascular disease risk factors in men and women with metabolic syndrome. Am J Clin Nutr 2008, 87:79-90.

27. Brinkworth GD, Buckley JD, Noakes M, Clifton PM, Wilson CJ: Long-term effects of a very low-carbohydrate diet and a low-fat diet on mood and cognitive function. Arch Intern Med 2009, 169:1873-1880.

28. Somerset SM, Graham L, Markwell K: Depression scores predict adherence in a dietary weight loss intervention trial. Clin Nutr 2011, 30:593-598.

29. Kupper N, Widdershoven JW, Pedersen SS: Cognitive/affective and somatic/affective symptom dimensions of depression are associated with current and future inflammation in heart failure patients. $J$ Affect Disord 2012, 136:567-576.

30. Skilton MR, Moulin P, Terra UL, Bonnet F: Associations between anxiety, depression, and the metabolic syndrome. Biol Psychiatry 2007, 62:1251-1257.

31. Morrison CD: Leptin signaling in brain: a link between nutrition and cognition? Biochim Biophys Acta 2009, 1792:401-408.

32. Milaneschi Y, Simonsick EM, Vogelzangs N, Strotmeyer ES, Yaffe K, Harris TB, Tolea Ml, Ferrucci L, Penninx BW: Leptin, abdominal obesity, and onset of depression in older men and women. J Clin Psychiatry 2012, 73:1205-1211.

33. Kullmann S, Heni M, Veit R, Ketterer C, Schick F, Haring HU, Fritsche A, Preiss $H$ : The obese brain: association of body mass index and insulin sensitivity with resting state network functional connectivity. Hum Brain Mapp 2012, 33:1052-1061.
34. Silva $\mathrm{N}$, Atlantis $\mathrm{E}$, Ismail $\mathrm{K}$ : A review of the association between depression and insulin resistance: pitfalls of secondary analyses or a promising new approach to prevention of type 2 diabetes? Curr Psychiatry Rep 2012, 14:8-14.

35. Clement K, Viguerie N, Poitou C, Carette C, Pelloux V, Curat CA, Sicard A, Rome S, Benis A, Zucker JD, Vidal H, Laville M, Barsh GS, Basdevant A, Stich $V$, Cancello R, Langin D: Weight loss regulates inflammation-related genes in white adipose tissue of obese subjects. FASEB J 2004, 18:1657-1669.

36. Perez-Cornago A, Zulet MA, Martinez JA: Association between mood and diet quality in subjects with metabolic syndrome participating in a behavioural weight-loss program; a cross-sectional assessment. Nutr Neurosci 2014, http://dx.doi.org/10.1179/1476830514Y.0000000116.

37. Swenne I, Rosling A, Tengblad S, Vessby B: Omega-3 polyunsaturated essential fatty acids are associated with depression in adolescents with eating disorders and weight loss. Acta Paediatr 2011, 100:1610-1615.

38. Bertone-Johnson ER, Powers SI, Spangler L, Brunner RL, Michael YL, Larson JC, Millen AE, Bueche MN, Salmoirago-Blotcher E, Liu S, Wassertheil-Smoller S, Ockene JK, Ockene I, Manson JE: Vitamin D intake from foods and supplements and depressive symptoms in a diverse population of older women. Am J Clin Nutr 2011, 94:1104-1112.

39. Amr M, El-Mogy A, Shams T, Vieira K, Lakhan SE: Efficacy of vitamin C as an adjunct to fluoxetine therapy in pediatric major depressive disorder: a randomized, double-blind, placebo-controlled pilot study. Nutr J 2013, 12:31.

40. Rosenberg DE, Bombardier CH, Artherholt S, Jensen MP, Motl RW: Selfreported depression and physical activity in adults with mobility impairments. Arch Phys Med Rehabil 2013, 94:731-736.

41. Appelhans BM, Whited MC, Schneider KL, Ma Y, Oleski JL, Merriam PA, Waring ME, Olendzki BC, Mann DM, Ockene IS, Pagoto SL: Depression severity, diet quality, and physical activity in women with obesity and depression. J Acad Nutr Diet 2012, 112:693-698.

doi:10.1186/1475-2891-13-36

Cite this article as: Perez-Cornago et al:: A decline in inflammation is associated with less depressive symptoms after a dietary intervention in metabolic syndrome patients: a longitudinal study. Nutrition Journal 2014 13:36.

\section{Submit your next manuscript to BioMed Central and take full advantage of:}

- Convenient online submission

- Thorough peer review

- No space constraints or color figure charges

- Immediate publication on acceptance

- Inclusion in PubMed, CAS, Scopus and Google Scholar

- Research which is freely available for redistribution 